\title{
ION AND ELECTRON BEAM PROCESSING OF CONDENSED MOLECULAR SOLIDS TO FORM THIN FILMS
}

Mi. W. Ruckman ${ }^{*}$ J. K Mowlem **, J. F. Moore**, D. R. Strongin ** and M. Strongin

* Physics Department, Brookhaven National Laboratory, Upton, New York 11973

** The State University of New York at Stony Brook, Department of ChemisfiEE CEIVED Stony Brook, New York 11794

\section{ABSTRACT}

Electron and ion beams can be used to deposit thin films and etch surfaces using gas phase precursors. However, the generation of undesirable gas phase products and the diffusion of the reactive species beyond the region irradiated by the electron or ion beam can limit selectivity. In this paper, the feasibility of processing condensed precursors such as diborane, tri-methyl aluminum, ammonia and water at $78 \mathrm{~K}$ with low energy ( $100-1000$ $\mathrm{eV}$ ) electron and ion beams ( $\mathrm{Ar}+, \mathrm{N}_{2}{ }^{+}$and $\mathrm{H}_{2}{ }^{+}$) ranging in current density from 50 $\mathrm{nA}$ to several $\mu \mathrm{a}$ per $\mathrm{cm}^{2}$ is examined. It was found that boron, boron nitride and stoichiometric aluminum oxide films could be deposited from the condensed volatile species using charged particle beams and some of the physical and chemical aspects and 1 . nitations of this new technique are discussed.

\section{INTRODUCTION}

Ion and electron beam processing of materials plays an important role in the fabrication of microelectronics and increasingly these techniques are being used to make nanosized structures [1]. High flux charged particle beams can be focused to submicron dimensions and are often used to construct prototype devices whose size plays an important part in governing their physical properties. Successful uses of ion beams in making micro structures include ion implantation and reactive ion etching. Electron beams are used to fabricate masks and pattern thin films. Electron and ion beams can be used to deposit thin films. Some of the limitations of using charged particle beams to selectively deposit thin films on a microscopic scale are obvious. The usual schemes for depositing thin films using ion beam or electron beam excitation of the gas phase precursors either coat the entire substrate ( i.e. plasma assisted chemical vapor deposition ( $p$-CVD)) or have a limited ability for making micro structures because the reactive chemical species can drift out of the energetic beam used to activate the gaseous precursors.

An alternative to gas phase precursors are solid precursors that can be converted to the desired product by 1) ele:tron, 2) inert ion or 3) reactive ion bombardment and successful fabrication of micro structures has been demonstrated for all of these techr ques [2]. One drawback of this approach is the fact that the non-converted precursor material remains on the substrate and either has to be suitable for another use in the structure (e.g. an insulator ) or readily removed from the substrate. Such materials could be made volatile and some tempe rature and be removed from the substrate by heating to that temperature. Gases often used in microelectronics fabrication can be condensed on sufficiently cold substrates ( e.g. 
$\mathrm{SiH}_{4}$ at $60 \mathrm{~K}$ ) and when activated by non-thermal means should in theory react to form useful inorganic coatings like silica or $\alpha-S i$.

This paper describes an examination of the feasibility of using low energy ion or electron beams to process molecular solids at cryogenic temperatures to make useful coatings. Electron and $\mathrm{Ar}+$ beams were used to convert condensed diborane $\left(\mathrm{B}_{2} \mathrm{H}_{6}\right)$ to a hydrogen-rich or boron film and $\mathrm{N}_{2}{ }^{+}$beams were used to convert condensed diborane to boron nitride. The work shows that condensed gases can be non-thermally activated and processed into the solid phase or that energetic ions can be used as reactants to convert molecular films into solids at extremely low temperatures.

\section{EXPERIMENTAL DETAILS}

The experiments were conducted in an ion and turbopumped vacuum system capable of reaching the $10^{-10}$ Torr range after vacuum bake out. Standard surface analytical tools for $x$-ray photoelectron spectroscopy (XPS) were available for analysis of the substrates and thin films at each stage of their processing. The electron beam source was the ionizer of a quadrupole mass spectrometer ( UTI-100C) which was biased to extract the electron beam. The sample was a silver foil which was attached to a copper cold finger using stycast epoxy. The entire cold finger and cryostat were isolated from the vacuum chamber using a ceramic vacuum break. The sample could be biased from $0-1000 \mathrm{~V}$ and this was used to vary the incident particle energy and focus the charged particle beam on the substrate. A sputter ion source operated at low energy was used to generate argon, nitrogen or hydrogen beams. When the samples were bombarded using ions, they were biased at - $250 \mathrm{~V}$. This was done not only to control the energy of the incident beam but to also repel electrons or negatively charged particles from striking the surface. Hence, we attribute the ion processing results to the positively charged species.

The cold finger was cooled to liquid nitrogen temperature $(-80 \mathrm{~K})$ and the silver foil sputtered with an $\mathrm{Ar}^{+}$beam to provide a clean surface. The absence of impurities was verified by XPS scans of the energy ranges where the 1s core levels of such impurities as $\mathrm{C}, \mathrm{N}$ and $\mathrm{O}$ are found. Next, the surfaces were coated with diborane which was condensed from a commercial $5 \% \mathrm{~B}_{2} \mathrm{H}_{6} / 95 \%$ Ar mixture. Lower temperatures than $80 \mathrm{~K}$ are needed to condense argon at these pressures, so the diborane films condensed were pure. Typical times required to condense seiveral monolayers of diborane were $400 \mathrm{~s}$ with a combined diborane/Ar partial pressure of $5 \times 10^{-5}$ Torr. The estimated diborane exposure was $10^{4} \mathrm{~L}\left(1 \mathrm{~L}=10^{6} \mathrm{Torr}-\mathrm{sec}\right)$. After the dilorane was administered to the surface, the vacuum chamber was pumped down and the $\mathrm{B}_{2} \mathrm{H}_{6}$ was irradiated with electrons or ions. At selected intervals the electron or ion bombardment was stopped and XPS scans done to study the electronic or compositional changes in the molecular solid. After substantial changes to the composition or electronic properties of the molecular layer, the liquid nitrogen was removed from the cryostat and the sample was allowed to warm up to a point where diborane should be thermally removed from the surface. As the data shows, the irradiation of condensed diborane films by energetic electrons or ions produces thermally stable frims whose XPS spectra resemble boron or boron nitride coatings. 


\section{RESULTS AND DISCUSSION}

Figure 1 shows the modification of the boron is core level for electron processing of a $\mathrm{B}_{2} \mathrm{H}_{6}$ film to make either a boron or a boron hydride coating which is not volatile at room temperature. The initial position of the boron is core level is at a binding energy of $-190.5 \mathrm{eV}$ and the width of the core level is several electron volts. Even with our modest resolution, it is apparent that the diborane interacts with the silver support and the resulting layer has several in equivalent local environments. When the film was allowed to warm up the molecular film desorbed from the surface between 100-110 K and the RGA cracking pattern was identical to diborane.

Electron irradiation caused the B is peak to shift to $-188 \mathrm{eV}$ binding energy. The sample was bombarded by $100 \mathrm{eV}$ electrons for $400 \mathrm{~s}$. and the electron current was $0.4 \mu \mathrm{A}$. Solid boron has a binding energy of $-188 \mathrm{eV}$ and it could be : concluded that electron bombardment causes the fragmentation oi diborane and the removal of hydrogen which in its molecular form is volatile at $80 \mathrm{~K}$. To determine whether diborane had been converted to elemental boron or a nonvolatile boron hydride (e.g. decaborane), the sample was warmed to $150 \mathrm{~K}$. The $\mathrm{B}$ 1s peak moved a few tenths of an $\mathrm{eV}$ to higher binding energy and decreased approximately $10-15 \%$ in intensity. A reference $\mathrm{B}_{2} \mathrm{H}_{6}$ film, not subjected to electron bombardment, was almost completely removed from the substrate at this temperature.

At this point we can only speculate about the physical mechanisms at work during the electron bombardment of the diborane. At a kinetic energy of $100 \mathrm{eV}$ the electrons greatly exceed the iypical

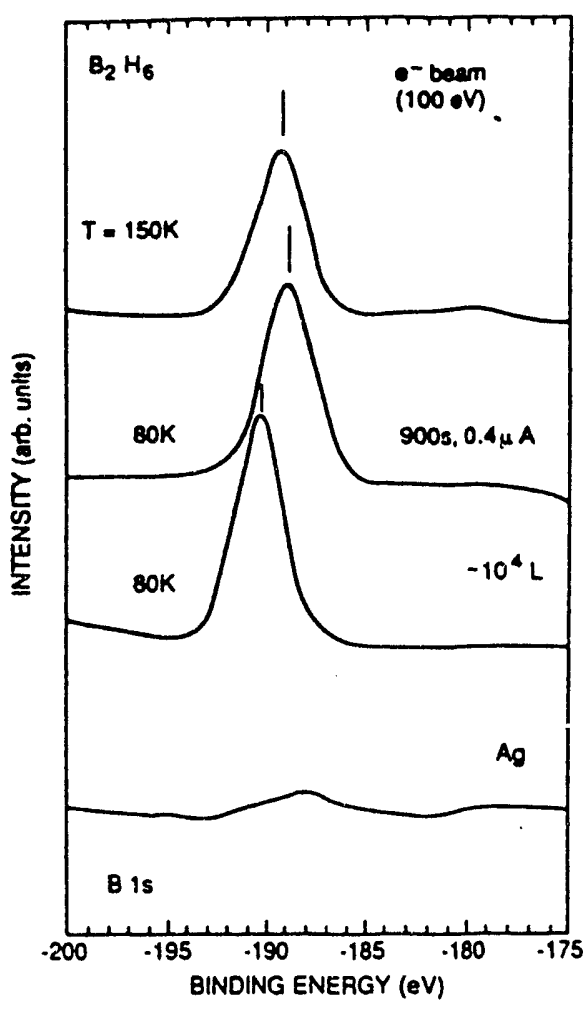

Figure 1. Conversion of condensed $\mathrm{B}_{2} \mathrm{H}_{6}$ to a boron or boron hydride by a low energy electron beam.

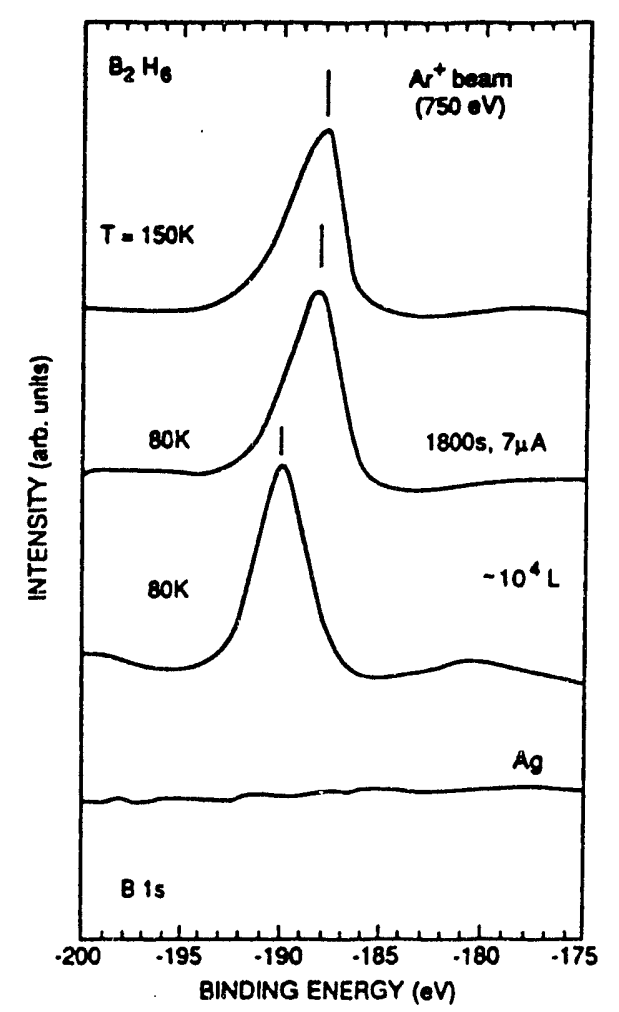

Figure 2. Conversion of solid $\mathrm{B}_{2} \mathrm{H}_{6}$ to a boron or boron hydride by a low evergy argon ion beam. 
thresholds for electron attachment or fragmentation of diborane by electrons [3]. An alternative means of activation of diborane in a condensed solid is bombardment by rare gas ions [4]. Such charged particles could exchange energy with the $\mathrm{B}_{2} \mathrm{H}_{6}$ molecules by collisions [5]. Rare gases have very high partial pressures at $80 \mathrm{~K}$ and are chemically inert. Hence, they should be easy to remove from thin surface layers.

Figure 2 shows the results obtained for bombarding a $\mathrm{B}_{2} \mathrm{H}_{6}$ film with $750 \mathrm{eV} \mathrm{Ar}{ }^{+}$ ions. As previously menticned the $\mathrm{Ar}^{+}$ source generated a $500 \mathrm{eV}$ beam which was accelerated by a 250 . V bias toward the sample. The same bias also repelled electrons produced by the $\mathrm{Ar}^{+}$source. The processing parameters were 1800s exposure time and an ion current of $7 \mu \mathrm{A}$. A similar boron film was produced and the amount of boron sputtered from the surface was small. Ion beam processing of molecular solids is limited by the small cohesive energy of most molecular solids which leads to sputtering when the ion energy exceeds a specific threshold. When the energy is low enough to avoid sputtering another concern is the amount of energy or momentum transferred to the molecular precursors by the incident ions. If the energy and momentum transfer are too small to get over the reaction activation barrier the ions will ricochet off the molecules and do nothing [6].

Incident ion beams can also act as a source of one of the reactants. Such a reactant would be very reactive and carry into the reaction the energy need to thermally activate the reaction [7]. It is possible, even at low ion energies to exceed the typical activation energies of chemical processes by at least an order of magnitude, so it may not only be possible to make

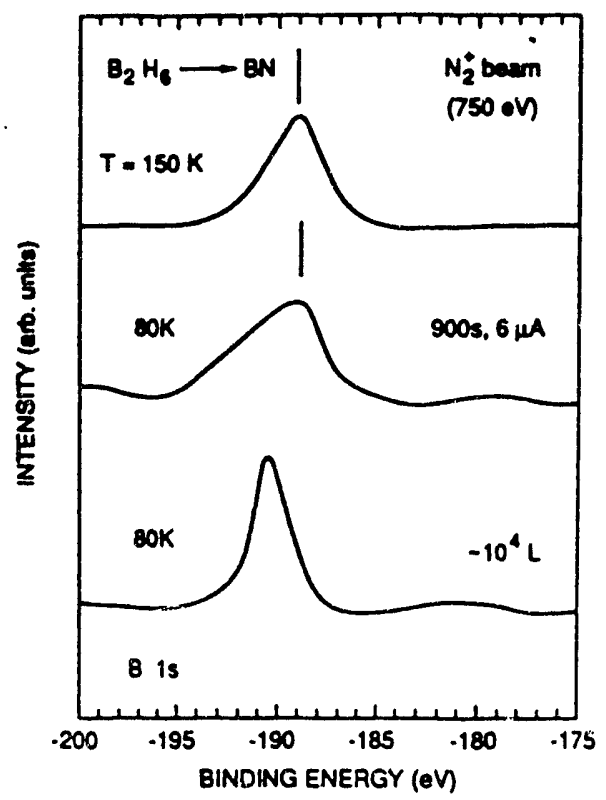

Figure 3. B 1s spectra for the reaction of a nitrogen ion beam with diborane to form boron nitride.

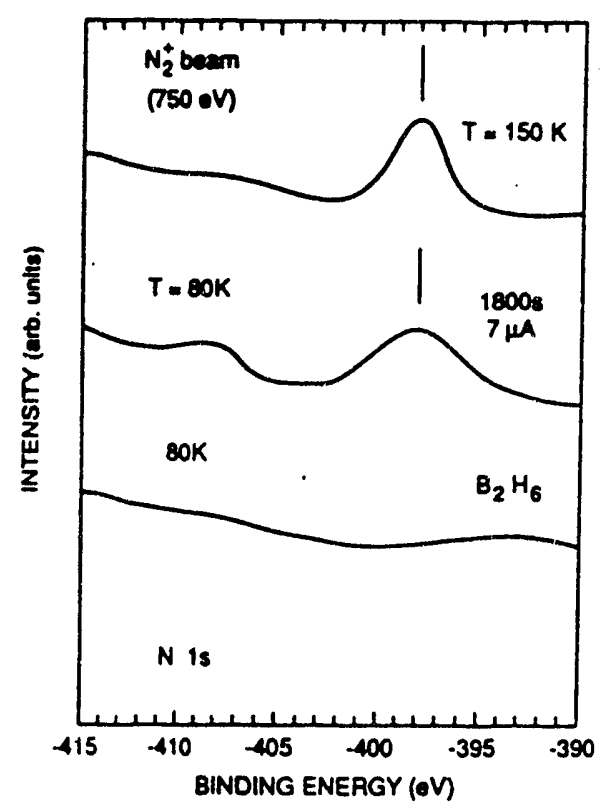

\begin{tabular}{l}
3 \\
$\delta$ \\
$-\pi$ \\
5 \\
5 \\
\hline
\end{tabular}

Figure 4. N $1 \mathrm{~s}$ spectra for the reaction of a nitrogen ion beam with diborane to form boron nitride. 
ordinary chemical compounds but also make new materials with different structures and properties. In the example described in figures 3 and 4, we demonstrate that a energetic $\mathrm{N}_{2}+$ beam can be reacted with diborane to make a thin film that resembles boron nitride. It should be emphasized that BN is representative of a class of hard materials like diamond that are normally produced using energetic species normally created in a plasma or synthesized under extreme thermal conditions. Figure 3 shows how the $B$ 1s core level is modified when condensed diborane is bombarded using nitrogen ions. The nitrogen ion processing lasted $900 \mathrm{~s}$. and the incident ion current was $6 \mu \mathrm{A}$. The B $1 \mathrm{~s}$ core level broadens and develops a pronounced asymmetry oriented towards lower binding energy. This is interpreted as the growth of another B 1s core level component at lower binding energy due to the formation of a new boron containing phase. An examination of the film for nitrogen finds that some nitrogen is retained in the diborane layer. The $\mathbf{N}$ 1s peak is initially centered at $-398 \mathrm{eV}$ binding energy and is relatively broad suggesting a series of nitrogen bonding configurations rather than a single B-N configuration. From the binding energy of the $\mathbf{N}$ is peak it is clear that the nitrogen has not reverted to molecular nitrogen and may have formed a nitride. At this point the nitrogen bombardment of the diborane film was halted and the nitrogen containing diborane film was heated to remove the unreacted diborane and other volatile components. This procedure changed the $B$ is peak and sharpened the $\mathrm{N}$ is line. The $\mathrm{B}$ 1s core level becomes much more symmetric and the resulting peak which resembles a Gaussian function is found at - $189 \mathrm{eV}$ binding energy. Typical values for BN range from - 190 to - $190.5 \mathrm{eV}$ [8]. However, B 1s binding energies as low as $-189 \mathrm{eV}$ reported by other workers [9] and thin BN films showing the characteristic $\mathrm{N}$ and $\mathrm{B}$ k-edges of boron nitride have the same binding energy [10]. The same considerations apply to the binding energy of the $\mathrm{N} 1 \mathrm{~s}$ peak. It is still centered at $398 \mathrm{eV}$ binding energy and has about the same width as the B 1s peak. The resulting film is non-volatile at $150 \mathrm{~K}$ and higher temperatures and this along with the photoelectron data makes a case for the formation of a thin BN layer.

Other systems were tried with varying degrees of success. In related work by our group using photon beams to activate reactions with condensed molecular films, alumina and silicon films were deposited using precursors like diborane and ammonia to make $\mathrm{BN}$ [10], tri-methyl aluminum (TMA) and water to make $\mathrm{Al}_{2} \mathrm{O}_{3}$ [11] and tetra-methyl silane and ammonia or water to make silicon or $\mathrm{SiO}_{2}$, respectively [12]. To determine whether charged particles could drive reactions in mixtures of molecular solids at low temperatures, an $\mathrm{Ar}+$ beam was directed into a TMA/ $\mathrm{H}_{2} \mathrm{O}$ mixture at $80 \mathrm{~K}$. We found that TMA and water interact at $80 \mathrm{~K}$ but form a compound which is volatile and contains significant amounts of carbon. In work using photon beams, a reaction liberating virtually all of the carbon as methane or $\mathrm{CO}$ and forming an aluminum oxide or related phase containing some hydrogen or hydroxyl was activated by the photon beam. When a $6 \mu \mathrm{A} 750 \mathrm{eV} \mathrm{Ar}+$ beam was directed into the TMA/H 20 mixture for 1800 s., XPS spectra showed evidence that the aluminum was converted to $\mathrm{Al}_{2} \mathrm{O}_{3}$ and some of the carbon was liberated from the film. The thickness of the film was reduced by sputtering and the loss of some material via the formation of methane or $\mathrm{CO}$. The aluminum oxide produced by this technique was 
thermally stable and remained on the surface after all of the volatile precursors and produces were removed from the surface by heating to $150 \mathrm{~K}$.

\section{CONCLUSIONS}

Electron, rare gas ion and nitrogen ion beams were used to process condensed diborane, into boron or boron nitride films. The volatile nature of the precursors facilitates the formation of small structures when focused charge particle beams are used to pattern the films because the films are selectively deposited only when activated by the charged particle beam. The unreacted material can be removed by allowing the sample to retum to $300 \mathrm{~K}$. Other potential advantages of this processing technique include the great reduction in the amounts of the precursor chemicals needed for processing and the elimination of activated precursors that can drift out of the charged particle beam. Other obvious advantages are related to the transport and elimination of the scattering of the charged particle beam when directed into a gas. This work is at an early stage and much remains to be done to establish the technique as a usable process for materials fabrication.

\section{ACKNOWLEDGMENTS}

This work was supported by the US Department of Energy, Division of Materials Sciences under contract No. DE-ACO2-76CH00016. DRS also acknowledges the support of National Science Foundation under a NYI award.

\section{REFERENCES}

[1] S. K. Ghandhi, "VLSI Fabrication Principles: Silicon and Gallium Arsenide", Wiley, New York, (1982).

[2] For examples see "Photons and Low Energy Particles in Surface Processing", C. Ashley, J. Brammon and S. Pang eds. MRS Symposium Proc. 236, Mat. Res. Soc., Pittsburgh, (1992).

[3] C. E. Melton, "Principles of Mass Spectroscopy and Negative Ions", Dekker, New York, (1970).

[4] J. W. Coburn and H. F. Winter, J. Appl. Phys., 50, 3189, (1979).

[5] E. W. McDaniel, "Collision Phenomena in Ionized Gases", Wiley, New York, (1964).

[6] D. J. Kester and R. Messier, J. Appl. Phys. 72, 504 (1992).

[7] V. F. Dorfmann, Thin Solid Films, 212, 267 (1992).

[8] D. N. Hendrickson, J. M. Hollander, and W. L. Jolly, Inorg. Chem. 2, 612 (1970).

[9] J. Barth, C. Kunz and T. M. Zimkina, Solid State Commun., 36, 453 (1980).;

K. Hamrin, G. Johansson, U. Gelius, C. Nordling and K. Siegbahn, Phys. Scripta, 1, 277 (1970).

[10] D. R. Strongin, J. K. Mowlem, M. W. Ruckman and Myron Strongin, Appl. Phys. Lett., 60, 256 (1992).

[11] D. R. Strongin, J. F. Moore and M. W. Ruckman, Appl. Phys. Lett., 61, 729 (1992).

[12] J. F. Moore, R. Krocyzski, D. R. Strongin and M. W. Ruckman ( unpublished ). 


\section{DISCLAIMER}

This report was prepared as an account of work sponsored by an agency of the United States Government. Neither the United States Government nor any agency thereof, nor any of heir employees, makes any warranty, express or implied, or assumes any legal liability or responsibility for the accuracy, completeness, or usefulness of any information, apparatus, product, or process disclosed, or represents that its use would not iriringe privately owned rights. Reference herein to any specific commercial product, process, or service by trade name, trademark, manufacturer, or otherwise does not necessarily constitute or imply its endorsement, recommendation, or favoring by the United States Government or any agency thereof. The views and opinions of authors expressed herein do not necessarily state or reflect those of the United States Government or any agency thereof. 

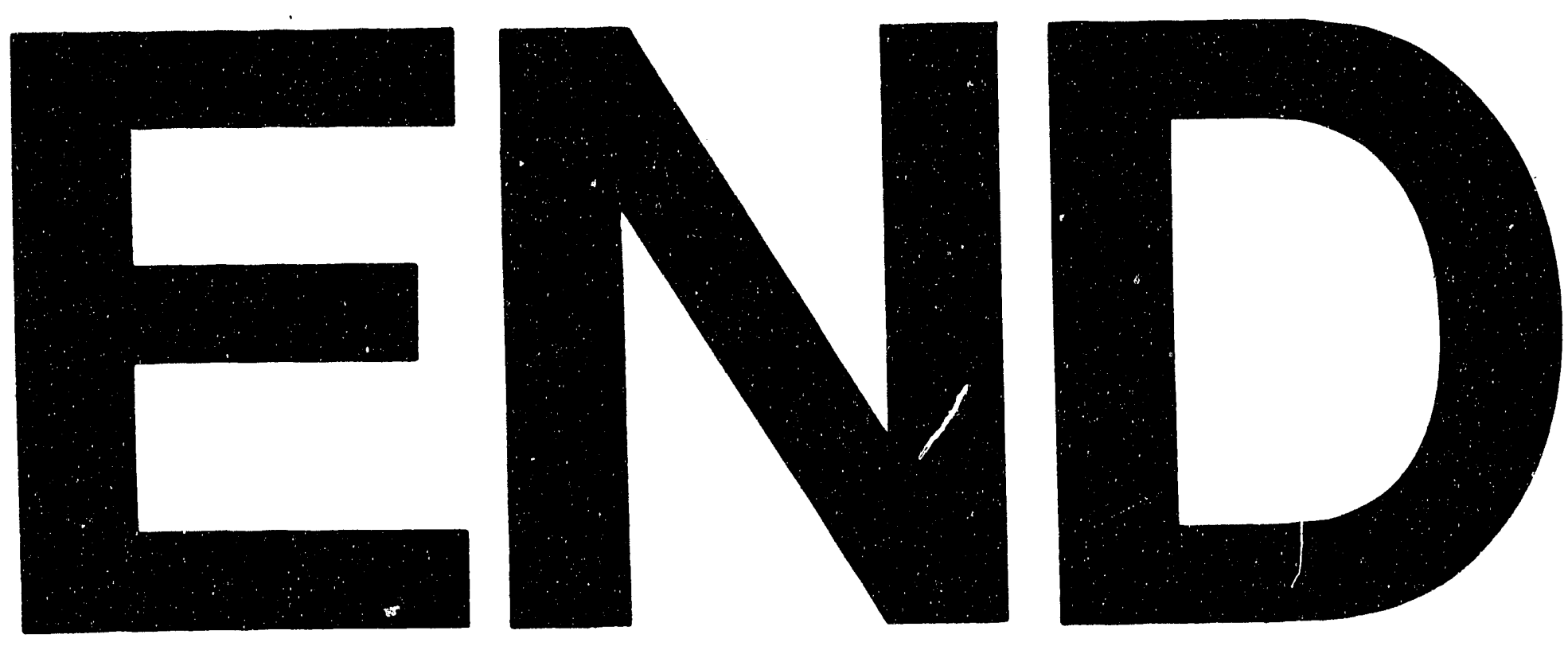

1
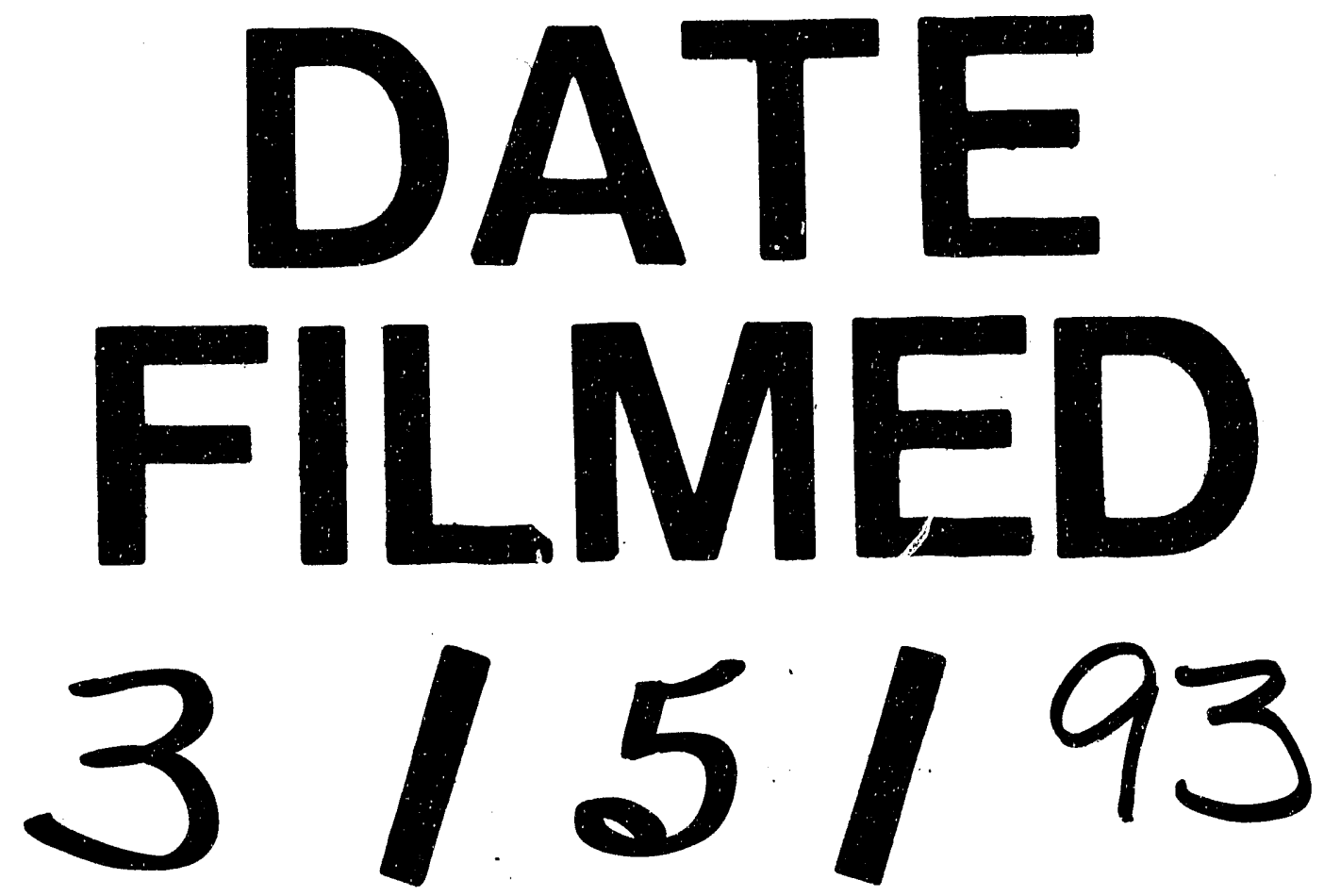
